\title{
Ambientalização curricular na Educação Superior: desafios e perspectivas
}

\section{Curricular greening in Higher Education: challenges and perspectives}

\author{
Antonio Fernando Silveira Guerra ${ }^{1}$ \\ Mara Lúcia Figueiredo ${ }^{2}$
}

\begin{abstract}
RESUMO
Este artigo pretende contribuir com a reflexão e o diálogo sobre o processo de ambientalização curricular, com foco nas Instituições de Educação Superior (IES). Ele apresenta uma contextualização de alguns marcos teóricos dessa temática, para, em seguida, descrever o panorama de trabalhos e experiências de ambientalização curricular nas universidades em diferentes países e de IES brasileiras que participam como instituições-elo da Rede Sul Brasileira de Educação Ambiental (REASul) e da Alianza de Redes Iberoamericanas por la Sustentabilidad y el Ambiente (ARIUSA). Ele discute os rumos da inserção da sustentabilidade socioambiental no processo de ambientalização curricular. Como resultados, este artigo indica alguns desafios e perspectivas desse processo na incorporação da cultura da sustentabilidade como política institucional nas universidades.
\end{abstract}

Palavras-chave: ambientalização; sustentabilidade; educação ambiental; currículo; educação superior.

\begin{abstract}
This article intends to contribute with the reflection and dialogue related to the process of curricular greening, with its focus on the Institutions of Higher Education [Instituições de Educação Superior (IES)]. We present a contextualization of some theoretical marks of this theme, followed by
\end{abstract}

DOI: $10.1590 / 0104-4060.38110$

1 Universidade do Vale do Itajaí. Itajaí, Santa Catarina, Brasil. Rua Uruguai, 458. CEP: 88302-901.

2 Centro Universitário de Brusque. Brusque, Santa Catarina, Brasil. Rua Dorval Luz, 123. CEP: $88352-400$. 
a panoramic description of work processes and experiences of curricular greening within universities in different countries and in Brazilian IES that participate as link institutions from REASul (South Brazilian Environmental Education Net) and from Alianza de Redes Iberoamericanas por la Sustentabilidad y el Ambiente (ARIUSA). The article discusses the paths of insertion of social-environmental sustainability in the actions of curricular greening. As results, some challenges and perspectives of this movement are indicated in the incorporation of the sustainability culture as an institutional policy within universities.

Keywords: greening; sustainability; environmental education; curriculum; higher education.

\section{Precedentes}

A temática ambiental integra o rol de preocupações e de discussões da sociedade atual. Frente à multicausalidade da crise ambiental, compreendida como uma crise civilizatória, e da racionalidade instrumental (LEFF, 2002), e, considerando que a espécie humana já extrapolou alguns dos limites dos sistemas para sustentabilidade da vida no planeta ${ }^{3}$ (ROCKSTRÖM et al., 2009), torna-se imprescindível repensar as intervenções, as práticas humanas e os seus efeitos sobre o ambiente natural em relação à preservação da vida e da biodiversidade, ameaçadas pelo modelo capitalista de produção, de consumo e de descarte, o que aumenta as injustiças ambientais. Pouco a pouco, a visão ingênua acerca dos problemas ambientais cede espaço a uma reflexão mais profunda, fundamentada e alicerçada em pressupostos teórico-epistemológicos, que viabilizem o alcance de valores sociais voltados à construção de uma sociedade de direitos, socialmente justa e sustentável.

De acordo com Leff (2002), a crise ambiental é um problema epistemológico que possibilita a discussão e a reflexão do conhecimento e dos saberes ambientais ${ }^{4}$. Assim, ao considerarmos o papel central do ensino superior nas universidades, na facilitação da construção do conhecimento e suas inúmeras funções e responsabilidades frente a uma sociedade mais justa, igualitária e

3 Segundo Rockström (2009), em artigo da revista Nature, a espécie humana extrapolou a capacidade de três dos nove sistemas planetários (emissão de $\mathrm{CO}_{2}$, erosão da biodiversidade e poluição por gases).

4 Para ele, "A crise ambiental é a crise de nosso tempo. [...] Por isso, a crise ambiental é acima de tudo um problema de conhecimento [...]" (LEFF, 2002, p. 191, grifos nossos). 
ética, torna-se indiscutível sua importância na inserção da dimensão ambiental em suas diversas frentes de atuação (ensino, pesquisa, extensão e gestão), conforme apontam alguns autores e autoras (TRISTÃO, 2007; MARCOMIN; SILVA, 2010; GUERRA; FIGUEIREDO, 2010; GUERRA; FIGUEIREDO; SAENZ, 2012, dentre outros).

Pelo exposto, a temática da ambientalização curricular nas universidades constitui uma linha de investigação e de ação, em que a Educação Ambiental (EA) assume um papel transformador e emancipatório, destacado nos princípios do "Tratado da Educação Ambiental para Sociedades Sustentáveis e Responsabilidade Global" (FÓRUM, 1992). No entanto, a despeito de todas as iniciativas e da sensibilização da sociedade e das políticas públicas de incorporação da Educação Ambiental (EA) de forma permanente nas práticas pedagógicas, as escolas e, em especial, as universidades encontram inúmeros obstáculos para tornar realidade a ambientalização curricular e o enraizamento da Educação Ambiental "em todos os níveis de ensino", como determinam a Política Nacional (BRASIL, 1999), o Programa Nacional de Educação Ambiental - ProNEA (BRASIL, 2005) e, mais recentemente, a Resolução n. 2, de 15 de junho de 2012, que estabelece as Diretrizes Curriculares Nacionais para a Educação Ambiental - DCNEA (BRASIL, 2012).

A ambientalização curricular compreende a inserção de conhecimentos, de critérios e de valores sociais, éticos, estéticos e ambientais nos estudos e currículos universitários, no sentido de educar para a sustentabilidade socioambiental ${ }^{5}$. Portanto, os Projetos Pedagógicos e os planos de ensino dos cursos deveriam conter conceitos e instrumentos curriculares que permitissem entender e apreciar o ambiente e sua complexidade, além de conteúdos que deixassem os estudantes compreenderem a relação entre a atividade humana e o ambiente, de maneira a integrar o fator ambiental em sua futura atividade profissional (BOLEA et al., 2004). No entanto, de acordo com esses autores, “[...] isso representa uma mudança radical na concepção e explicação de muitas das disciplinas lecionadas na Universidade" (BOLEA et al., 2004, p. 444). Ambientalizar o currículo não é uma ideia nova, mas transformadora, pois significa instaurar, no sistema educativo, uma série de mudanças que incluam:

[...] inovações conceituais, metodológicas e atitudinais, mas também estruturais e organizacionais, que permitam um enfoque interdisciplinar

5 Coerentes com os princípios do ProNEA, utilizamos a expressão sustentabilidade socioambiental como contraponto à noção de desenvolvimento sustentável (DS), popularizada com o Relatório Brundtland (BRUNDTLAND, G. H. Our Common Future. Oxford: Oxford University Press, 1987) e pelos governos na Conferência das Nações Unidas, a Rio 92. 
no currículo, que facilite um planejamento global de objetivos e conteúdos, que se aproxime da compreensão da complexidade e da visão planetária [...] que facilitem a descentralização e a flexibilidade do currículo necessárias para adaptar-se ao entorno e dar respostas as suas inquietudes. (GONZÁLES MUÑOZ, 1996, p. 37).

Frente a esse desafio, este artigo tem o objetivo de promover um diálogo sobre a necessidade de uma retomada dos estudos relacionados à ambientalização curricular, de forma a compreender melhor esse conceito e as perspectivas desse processo, na incorporação da cultura da sustentabilidade socioambiental como política institucional nas universidades.

\section{Ambientalização curricular: da construção do conceito ao desafio da institucionalização}

A temática da ambientalização curricular constitui-se, por si só, um campo profícuo de investigação. Podemos considerar a gênese do surgimento desse termo no esforço pioneiro de pesquisadores(as) de vários países na constituição da Rede de Ambientalização Curricular do Ensino Superior (ACES). Essa rede foi constituída em 2002 com o objetivo de apresentar um projeto comum ao Programa ALFA da União Europeia sob o título Programa de Ambientalização Curricular do Ensino Superior: proposta de intervenções e análises do processo, envolvendo 11 universidades, sendo cinco europeias e seis latino-americanas, das quais três eram brasileiras (UNESP - Universidade Estadual Paulista, UNICAMP - Universidade Estadual de Campinas e UFSCar - Universidade Federal de São Carlos). O projeto teve como finalidade elaborar metodologias de análises para avaliar o grau de ambientalização curricular dos Estudos Superiores na América Latina e Europa (GELI, 2002). De acordo com essa autora,

A colaboração entre as onze universidades que participam no projeto ACES [...] permite realizar um trabalho conjunto entre instituições que partem de realidades e situações diversas e contrastar os pontos de vista, os projetos e as estratégias ambientalizadoras das instituições que participam no programa. (GELI, 2002, p. 17). 
A trajetória e a produção científica desse grupo (ARBAT; GELI, 2002; JUNYENT; GELI; ARBAT, 2003; GELI; JUNYENT; SÁNCHES, 2003), registradas no sítio da rede ${ }^{6}$, legaram-nos referenciais importantes para a ambientalização em universidades no exterior e especialmente no Brasil. Pesquisadores(as) na UNESP de Rio Claro (CARVALHO; CAVALARI; SANTANA, 2003), na UNICAMP (AMORIM; ARBAT, 2003) e na UFSCar (FREITAS et al., 2003) discutiram essa temática e forneceram elementos e estratégias para o diagnóstico e constituição de um currículo ambientalizado. Entretanto, depois de amplos debates, os pesquisadores da rede ACES não chegaram a uma única definição, mas sim a quatro, dentre as quais destacamos a seguinte:

[...] ambientalização curricular é um processo contínuo de produção cultural voltado à formação de profissionais comprometidos com a completa busca das melhores relações possiveis entre a sociedade e a natureza, atendendo aos valores da justiça, da solidariedade e da equidade, aplicando os princípios éticos universalmente reconhecidos e o respeito às diversidades (JUNYENT; GELI; ARBAT, 2003, p. 21, grifos dos autores, tradução nossa).

No referido projeto, os pesquisadores estabeleceram metodologias para a análise do grau de ambientalização dos cursos superiores das IES participantes, que incluíam 10 características para que um curso fosse considerado ambientalizado $^{7}$ (JUNYENT; GELI; ARBAT, 2003). Essas 10 características ou indicadores e seus critérios para constituição de um guia para um currículo ambientalizado podem ser representadas pelo Diagrama Circular da Figura 1.

A forma circular do Diagrama permite-nos

[...] pensar sobre os diferentes elementos sem hierarquia prévia, e sim a partir de uma relevância igualitária. As linhas descontínuas permitem a expressão visual da permeabilidade e facilitam a percepção de um rico

6 Disponível em: <http://insma.udg.es/ambientalitzacio/web_alfastinas/castella/c_index. $\mathrm{htm} \geq$. Acesso em: 14/05/2014.

7 São elas: 1. Compromisso para a transformação das relações sociedade-natureza; 2. Complexidade; 3 . Ordem disciplinar (flexibilidade e permeabilidade); 4. Contextualização local e global; 5. Consideração do sujeito na construção do conhecimento; 6. Consideração aos aspectos cognitivos e afetivos das pessoas; 7. Coerência e reconstrução entre teoria e prática; 8. Orientação de cenários alternativos; 9. Adequação metodológica; e 10. Espaços de reflexão e participação democrática. (JUNYENT; GELI; ARBAT, 2003, p. 22, tradução nossa). 


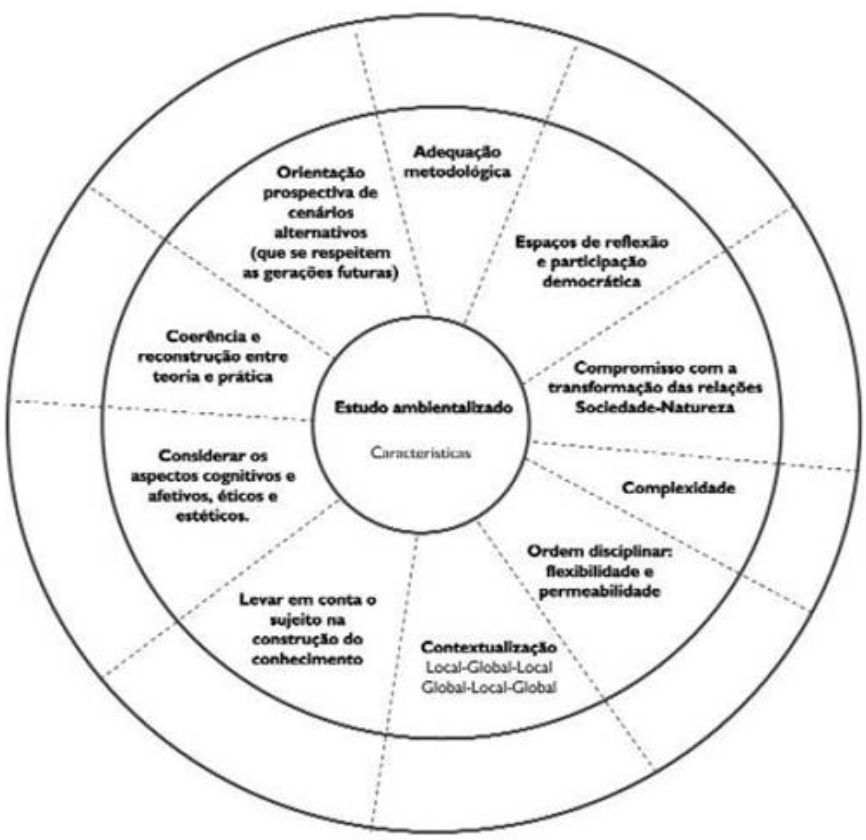

FIGURA 1 - DIAGRAMA CIRCULAR DAS CARACTERÍSTICAS DE UM CURRÍCULO AMBIENTALIZADO

FONTE: OLIVEIRA JUNIOR et al. (2003, p. 41).

conjunto que pode ser produzido a partir das especificidades de cada característica. (OLIVEIRA JUNIOR et al., 2003, p. 43).

O diagrama constitui a valorização da diversidade como elemento que integra, ao mesmo tempo, as semelhanças e as diferenças entre as instituições participantes. Nesse sentido, as IES adaptaram esse diagrama à sua própria realidade, adicionando novas características ou suprimindo-as, ao realizar esta movimentação na maioria dos casos, incluindo as características em outros âmbitos (OLIVEIRA JUNIOR et al., 2003).

O estudo da noção de ambientalização e da ambientalização curricular pode ser identificado na literatura, na Educação Básica (SANMARTÍ; PUJOL, 2002; COPELLO-LEVY, 2004, 2006) e, recentemente, pesquisas foram retomadas na Educação Superior no Brasil (PAVESI; FARIAS; OLIVEIRA, 2006; 
KITZMANN, 2007; MARCOMIN; SILVA, 2010; KITZMANN; ASMUS, 2012; GUERRA; FIGUEIREDO; SCHMIDT, 2012a, 2012b; dentre outros).

Kitzmann (2007, p. 553), ao "avaliar o processo de ambientalização em sistemas formais e não-formais de ensino", discute os conceitos de ambientalização e de Educação Ambiental formal e não formal, procurando identificar a integração da dimensão ambiental em diferentes níveis e espaços educativos. Além disso, busca "[...] analisar as propostas de Ambientalização Curricular de um curso técnico profissionalizante do Serviço Nacional de Aprendizagem Comercial - SENAC com base nos estudos da Rede ACES" (KITZMANN, 2007, p. 553).

A referida autora defende a noção de que ambientalizar o ensino significa "inserir a dimensão socioambiental onde ela não existe ou está tratada de forma inadequada" (KITZMANN, 2007, p. 554), o que exige mudanças administrativas e estruturais nas IES. Desse modo, percebe-se que é necessário que o "processo de ambientalização esteja norteado em critérios e princípios definidos de forma clara e abrangente, assim como ser realizado de forma sistêmica, considerando tanto a reforma curricular quanto a institucional, de modo a garantir a sua adequada implementação" (KITZMANN, 2007, p. 553-554). Nesse sentido, além das mudanças curriculares, é preciso efetuar mudanças estruturais relacionadas à aprendizagem da temática ambiental.

Nessa perspectiva, e reforçando o pensamento da autora, Guerra, Figueiredo e Schmidt (2012a, 2012b) enfatizam a importância da articulação de esforços entre diferentes atores (docentes, discentes e pesquisadores das Universidades e professores da Educação Básica) no aperfeiçoamento dos conhecimentos adquiridos na universidade com a integração e a melhoria do ensino da Educação Básica. Essa posição é demonstrada no trabalho desses autores com a utilização e a validação de um material pedagógico em suporte multimidiático (CD-ROM), com o tema gerador sustentabilidade, junto a bolsistas de 10 cursos de licenciatura vinculados ao Programa de Bolsas de Incentivo à Docência (PIBID) da Universidade Federal do Rio Grande (FURG). Em nosso entendimento, trabalhos com essa temática são importantes para:

[...] que se possa avançar, superar o obstáculo da fragmentação, estabelecendo um diálogo de saberes que torne realidade o processo de ambientalização dos cursos de Licenciatura de nossas universidades, e a formação continuada e atualização de professores(as) educadores(as) ambientais das redes públicas de ensino. (GUERRA; FIGUEIREDO; SCHMIDT, 2012b, p. 256). 
Kitzmann e Asmus (2012) definem ambientalização curricular como um processo de inovação por meio de intervenções que visam integrar temas socioambientais aos conteúdos e às práticas das instituições de ensino. Para eles, a ambientalização deve promover um questionamento constante e aberto sobre os conhecimentos e suas produções, tendo em vista o favorecimento da formação integral dos estudantes em seus diferentes níveis escolares. Por essa razão, esse processo deve ocorrer não somente na esfera curricular, mas nas diferentes instâncias do processo educativo, requerendo, assim, a ampliação do conceito de ambientalização curricular para ambientalização de todo o campus universitário.

Portanto, a ambientalização da universidade envolve não só o currículo, mas a pesquisa, a extensão e a gestão ambiental do campus universitário, como um processo contínuo e dinâmico, que pode auxiliar na transição das instituições de ensino para tornarem-se autênticos "espaços educadores sustentáveis". Esses espaços são aqueles que têm "[...] a intencionalidade pedagógica de se constituir em referências concretas de sustentabilidade socioambiental" (TRAJBER; SATO, 2010, p. 71).

A Resolução aprovada pelo Conselho Nacional de Educação (CNE) que institui as Diretrizes Curriculares Nacionais para a Educação Ambiental DCNEA (BRASIL, 2012), lançadas durante a Conferência das Nações Unidas sobre Desenvolvimento Sustentável, Rio+20, não utiliza diretamente o termo ambientalização. No entanto, entendemos que, em seu artigo 21 , remete a esse conceito, quando determina que:

Os sistemas de ensino devem promover as condições para que suas instituições educacionais se constituam em espaços educadores sustentáveis, com a intencionalidade de educar para a sustentabilidade socioambiental de suas comunidades, integrando currículos, gestão e edificações, em relação equilibrada com o meio ambiente e tornando-se referência para seu território. (BRASIL, 2012, p. 7).

Nesse sentido, as Diretrizes orientam os sistemas de ensino a garantir a inserção dos conhecimentos concernentes à Educação Ambiental nos currículos de todas as áreas da Educação Básica e da Educação Superior pela transversalidade, mediante temas relacionados ao meio ambiente e à sustentabilidade socioambiental, como conteúdo dos componentes constantes do currículo, e pela combinação de transversalidade e de tratamento nos componentes curriculares. Para isso, recomenda que, no planejamento e na gestão, sejam considerados os saberes e os valores da sustentabilidade, a diversidade de manifestações da vida, 
os princípios e os objetivos estabelecidos nas Políticas educacionais. Assume, também, a transversalidade da EA em todos os níveis de ensino, assim como o investimento na formação de professores.

Assim, a Educação Ambiental passa a integrar efetivamente a proposta pedagógica das instituições de ensino, da Educação Infantil à Educação Superior, interdisciplinar e transversalmente. Essas orientações exigem uma atuação mais ampla na escola e na universidade, o que só é possível por meio da formação inicial e continuada, uma sólida formação teórico-metodológica sobre as questões ambientais e de sustentabilidade, a identificação de estratégias e recursos, e o desenvolvimento de práticas pedagógicas inovadoras voltadas à sustentabilidade em suas diferentes dimensões (GUERRA; FIGUEIREDO; SCHMIDT, 2012b).

Acreditamos que, em atenção aos desafios das DCNEAs, para que elas se constituam como política pública, definindo os marcos legais, as diretrizes e os princípios pedagógicos, e reafirmando que a EA deve ocorrer em todos os níveis de ensino, novos desafios estão postos para os educadores no sentido de institucionalizar a ambientalização curricular na Educação Básica e Superior, com uma maior articulação entre o campo ambiental e o educacional. Desse modo, esse processo contínuo de ambientalização poderá propiciar à comunidade escolar e universitária vivências não só de práticas, mas também de princípios, de atitudes e de valores da sustentabilidade que sejam incorporados por uma sociedade que vive além dos seus muros.

\section{Um breve panorama do processo de ambientalização nas universidades}

Frente à discussão do conceito e do processo de ambientalização nas universidades, voltamos nosso olhar às parcerias entre pesquisadores em redes, alguns projetos de pesquisas e trabalhos apresentados em três eventos: na II Jornada Ibero-Americana da Alianza de Redes Iberoamericanas por la Sustentabilidad y el Ambiente - ARIUSA ${ }^{8}$ (GUERRA; FIGUEIREDO; SAENZ, 2012) e nas publicações produzidas na terceira e na quarta edições do Seminário Sustentabilidade nas Universidades (LEME et al., 2012; RUSCHEINSKY et al.,

8 A II Jornada Ibero-Americana da ARIUSA, realizada na Universidade do Vale do Itajaí, com apoio das demais IES que formam a Rede Sul Brasileira de Educação Ambiental - REASul, teve como objetivo compartilhar experiências relevantes de ambientalização nas atividades de ensino, pesquisa, extensão e gestão ambientais promovidas nas IES que atuam no âmbito ibérico, latino-americano e caribenho. Participaram 117 pesquisadores de 10 países (Brasil, Colômbia, Argentina, México, Espanha, Equador, Chile, Costa Rica, Guatemala e Cuba). 
2014). Nossa escolha por esses eventos justifica-se uma vez que as pesquisas apresentadas revelam um importante cenário de discussão sobre o tema, com contribuições de pesquisadores(as) de diferentes países. Essa produção constitui o estado da arte desse tema no contexto ibero-latino-americano, cuja discussão nos remete à reflexão sobre a importância da retomada dos estudos da ambientalização nas IES, e do compromisso das universidades com a sustentabilidade socioambiental em suas políticas. Na II Jornada da ARIUSA, Sáenz e Benayas relatam:

O processo de incorporação da dimensão ambiental nas instituições de educação superior (IES) na América Latina e no Caribe (ALC) iniciou-se no começo da década de 1950 e se desenvolveu por meio de três etapas que se caracterizam por estar centradas sucessivamente nos recursos naturais, no meio ambiente e no desenvolvimento sustentável. [...] de 1950 em diante, as universidades da Colômbia começaram a oferecer os primeiros programas de formação técnica e profissional para o aproveitamento e conservação dos recursos naturais. Assim, durante as décadas de cinquenta e sessenta foram criados, naquele país, 26 programas acadêmicos relativos a esses temas, em 14 diferentes IES. (SÁENZ; BENAYAS, 2012, p. 31, tradução nossa).

Ainda, segundo esses autores, no referido período, avanços semelhantes ou superiores foram observados em outros países da América Latina, iniciando a Educação Ambiental propriamente dita, nos anos 1970, em um processo simultâneo no âmbito internacional. O início da "[...] terceira etapa do processo de 'ambientalização' das universidades latino-americanas” (SÁENZ; BENAYAS, 2012, p. 31) tem como marco a Conferência das Nações Unidas para o Meio Ambiente Humano (CNUMAD), conhecida como Rio 92. Eles enfatizam que, infelizmente, publicações referentes a esse importante processo de ambientalização da educação superior na America Latina é escasso na literatura, de onde resulta a necessidade urgente de realização de novos estudos sobre os diferentes aspectos da incorporação da dimensão ambiental nas universidades latino-americanas (SÁENZ; BENAYAS, 2012).

Em torno da incorporação da sustentabilidade socioambiental na Educação Superior, e com um espírito de cooperação internacional, as redes de universidades integram-se à ARIUSA, cuja rede associada no Brasil é a Rede Sul Brasileira de Educação Ambiental (REASul), com 14 IES-elos participando efetivamente como membros da ARIUSA. 
Da iniciativa de um projeto de cooperação internacional envolvendo o Programa USP Recicla na Universidade de São Paulo, o Departamento de Ecologia da Universidade Autônoma de Madri (UAM/Espanha) e a parceria da PUCRS, surge o III Seminário Sustentabilidade nas universidades ${ }^{9}$, em novembro de 2011, de cujo evento membros da REASul e da ARIUSA participaram e no qual é apresentada a Plataforma informação, sensibilização e avaliação da sustentabilidade nas universidades ${ }^{10}$.

A temática da ambientalização, os debates e o intercâmbio de ideias que sucederam o referido Seminário reuniram em uma parceria pesquisadores de IES da REASul - Universidade do Vale do Itajaí (Univali), Unisinos e Centro Universitário de Brusque (Unifebe) com a USP São Carlos - no desenvolvimento de um projeto de pesquisa ${ }^{11}$, iniciado em 2013, que tem como objetivos analisar os documentos curriculares dos cursos de graduação; identificar abordagens e metodologias relacionadas à sustentabilidade e definir critérios, indicadores, estratégias e ações aplicáveis às IES. A REASul também promoveu uma Reunião de trabalho sobre Ambientalização, Sustentabilidade, Educação ambiental e Universidade em Santa Catarina - Análise, levantamento de estratégias e busca de novos rumos, na Univille, Campus Joinville/SC ${ }^{12}$.

Paralelamente a esse movimento, as universidades espanholas desenvolveram indicadores de avaliação das políticas universitárias de sustentabilidade (CADEP, 2010). Por iniciativa de pesquisadores desse grupo, em dezembro de 2012, a ARIUSA cria a Red de Indicadores de Sostenibilidad en las Universidades (Red RISU) e passa a integrar a Alianza Mundial de Universidades sobre Ambiente y Sostenibilidad (GUPES), uma iniciativa do Programa das Nações Unidas para o Meio Ambiente (PNUMA) e da Rede de Formación Ambiental para America Latina y el Caribe.

9 Os Seminários Sustentabilidade na Universidade originaram-se de um projeto financiado pela Agência Espanhola de Cooperação Internacional para o Desenvolvimento (AECID), com o objetivo de empreender esforços de cooperação e fortalecimento nas áreas de gestão, educação e participação ambiental em ambas as instituições, orientando-as para a incorporação de medidas sustentáveis em seus processos (FIGUEIREDO; GUERRA; CARLETTO, 2014).

$10 \mathrm{O}$ acesso à Plataforma está disponível pelo sítio: $<$ http://www.projetosustentabilidade. sc.usp.br>. Acesso em: 15/05/2014.

11 Trata-se do projeto Ambientalização e Sustentabilidade nas Universidades: Subsidios e Compromissos com Boas Práticas Ambientais, financiado pelo Conselho Nacional de Desenvolvimento Científico e Tecnológico (CNPq).

12 A reunião teve a participação de 12 IES do Sistema ACAFE (Associação Catarinense Fundação Educacional) e da UNESP de Tupã-SP e produziu a "Carta de Joinville, com os seguintes encaminhamentos: constituir um Fórum de discussão sobre ambientalização e sustentabilidade nas IES do Sistema ACAFE; elaborar projetos interinstitucionais de pesquisa sobre a temática; integrar projetos e ações de sustentabilidade socioambiental com as políticas institucionais das IES. 
Na reunião da Rede ARIUSA, em Vila de Leyva, na Colômbia, em dezembro de 2012, pesquisadores da Univali, da USP São Carlos, da Unisinos e da Unifebe assumiram a organização do IV Seminário Sustentabilidade na Universidade: Desafios à Ambientalização nas Instituições de Ensino Superior no Brasil ${ }^{13}$. Nesse evento, o conceito de ambientalização ganha destaque nos Grupos de Trabalho (GT), especialmente no GT 2: A incorporação da sustentabilidade socioambiental no currículo da graduação e pós-graduação (ambientalização curricular).

Em 2013, um projeto da Red RISU ${ }^{14}$ discutiu e adaptou os indicadores da Comisión Sectorial de Calidad Ambiental, Desarrollo Sostenible y Prevención de Riesgos (CADEP) ${ }^{15}$ ao contexto das universidades latino-americanas e do Caribe, envolvendo 80 universidades de 10 países: Chile, Brasil, Venezuela, Costa Rica, República Dominicana, Argentina, Peru, Colômbia, Guatemala e México. No Brasil, dez IES vinculadas à REASul e três convidadas participam do projeto sob a coordenação da Universidade do Vale do Itajaí (Univali).

Carvalho e Silva (2014) destacam a importância desse movimento das Jornadas e Seminários sobre a sustentabilidade e ambientalização nas universidades:

[...] a reunião de todos esses atores, iniciativas, redes e pesquisas no IV Seminário é parte de um processo de produção de conceitos e indicadores de sustentabilidade na universidade que está em curso, que, nesse momento, agrega uma nova rede (ARIUSA/GUPES) e que promete a abertura de novos estudos sobre indicadores de sustentabilidade na América Latina e Caribe, em diálogo com o estudo realizado na Espanha. (CARVALHO; SILVA, 2014, p. 125).

$13 \mathrm{O}$ evento foi realizado em Porto Seguro (BA), com o apoio da REASul e ARIUSA e contou com a participação de pesquisadores de 51 IES (18 da região Sudeste, 13 do Nordeste, 12 do Sul, 6 do Centro-Oeste e 2 do Norte), de Secretarias de Educação e da Coordenação Geral de Educação Ambiental (CGEA) do MEC.

14 Trata-se do Projeto Definición de indicadores y evaluación de los compromisos con la sostenibilidad en Universidades Latinoamericanas, sob a coordenação do Prof. Dr. Javier Benayas del Alamo, da Universidad Autónoma de Madrid (UAM - Espanha).

15 Os indicadores foram estruturados em três grandes áreas: organização, docência e pesquisa e gestão ambiental na universidade. Os 114 indicadores constituem 12 dimensões da sustentabilidade relacionadas com os campos da política institucional, sensibilização e participação da comunidade universitária, responsabilidade socioambiental, docência, pesquisa e extensão, transferência de tecnologia e a gestão ambiental (biodiversidade, energia, água, mobilidade, resíduos, compras verdes, urbanismo, impacto ambiental das instalações universitárias, dentre outros). 
Face ao exposto, verifica-se que o trabalho pioneiro dos pesquisadores da Rede ACES foi retomado nos últimos anos graças à articulação das redes de universidades e à socialização da produção científica sobre ambientalização e ao compromisso com sua institucionalização nas IES. Entretanto, Santos e Freitas (2014), citando Documento Técnico elaborado por Lipai (2013), alertam que de 31 IES públicas federais, apenas 33\% delas indicaram a presença da sustentabilidade ambiental no Plano de Desenvolvimento Institucional (PDI) - um documento estratégico orientador das ações nas IES ${ }^{16}$.

\section{Algumas considerações sobre um processo ainda inconcluso}

Esse trabalho soma-se a outros que indicam que, na atualidade, a questão do movimento de ambientalização curricular e sustentabilidade nas universidades aponta para uma releitura do conceito e ampliação ou inovação do modelo de indicadores da Rede ACES, avançando, assim, no processo de incorporação da cultura da sustentabilidade nas IES, para assumirem seu compromisso com a sustentabilidade socioambiental.

Os artigos resultantes dos eventos citados e a iniciativa de trabalhos cooperativos em redes de universidades contribuem para que avancemos nas discussões no sentido de alcançar, em médio prazo, a almejada inserção da temática ambiental e da sustentabilidade socioambiental na construção de uma cultura ambiental nas universidades.

As reflexões e comentários sobre os trabalhos de ambientalização apresentados neste artigo demonstram a existência de uma preocupação da universidade, como instituição social e comunitária, em realizar o processo de ambientalização e a inserção da sustentabilidade na comunidade universitária e em seu entorno.

No entanto, embora tenhamos avançado na dimensão da gestão ambiental para a sustentabilidade - como é o caso de IES brasileiras como a Universidade de São Paulo (USP), a Universidade Federal de São Carlos (UFSCar), a Uni-

16 Segundo os autores: "Em relação à natureza das ações, a maioria é da área curricular (84\%), seguida de gestão (15\%) e edificações (1\%). Das ações de currículo, mais da metade refere-se à extensão. As ações de gestão, em sua maioria, são voltadas para uso e descarte da água, resíduos sólidos e químicos, aquisição de bens e administração do campus. Pouco foi mencionado sobre as questões concernentes aos processos decisórios/gestão democrática. Quanto às edificações, o foco estava na ecoeficiência energética dos prédios" (SANTOS; FREITAS, 2014, p. 289). Cf. LIPAI, E. Produto n. 1) Documento Técnico contendo estudo sobre as possibilidades de engenharia de oferta (modelos) para os cursos de extensão, aperfeiçoamento e especialização disponibilizados pela Educação Ambiental no âmbito da Rede de Educação para Diversidades, 2013 - não publicado. 
sinos, a Pontifícia Universidade Católica do Rio Grande do Sul (PUC-RS), a Pontifícia Universidade Católica de Minas Gerais (PUC-Minas), a Universidade Estadual Paulista (Unesp), dentre outras -, quando se trata da ambientalização na organização curricular, depara-se com um hiato entre a efetiva inserção dessa temática nos documentos curriculares e nas práticas docentes e o que recomendam as Diretrizes Curriculares e as exigências do MEC-INEP para avaliação e recredenciamento dos cursos no que se refere à integração da Educação Ambiental nas disciplinas dos cursos de graduação "de modo transversal, contínuo e permanente".

Em decorrência do mencionado, dentre outros fatores tratados neste artigo, concordamos com Kitzmann (2007) que a ambientalização na universidade deve ser um processo contínuo e dinâmico. Contudo, ele não pode ocorrer somente na esfera curricular, mas nas diferentes instâncias do processo educativo (ensino, pesquisa, extensão, gestão ambiental e administração), requerendo, assim, a ampliação do conceito de ambientalização curricular para ambientalização de todo o campus (KITZMANN; ASMUS, 2012).

Concordamos, também, com a recomendação de Oliveira (2006) de que é necessária a definição de critérios e de indicadores para a ambientalização que se constituam como subsídios para a formulação e/ou fortalecimento de políticas públicas e de políticas institucionais comprometidas com a ambientalização. Assim, as políticas ambientais das universidades devem estar sintonizadas e em articulação com as políticas públicas em Educação Ambiental e meio ambiente (FIGUEIREDO; GUERRA; CARLETTO, 2014). Diante dessa argumentação, consideramos necessário que "[...] o espaço da escola [e da universidade] seja repensado em sua articulação com o currículo, de acordo com as premissas da sustentabilidade socioambiental, gerando uma nova cultura na comunidade escolar" (TRAJBER; SATO, 2010 p. 72).

Para concluir, é importante ressaltar que o processo de ambientalização exige flexibilidade, diálogo de saberes, sociabilização de conhecimentos de diferentes áreas, mudanças de atitudes e estilos de vida e vivência de princípios e valores ambientais. Além disso, o compromisso de toda a comunidade universitária e escolar na transformação da realidade e na incorporação da cultura da sustentabilidade socioambiental como política institucional nas universidades. 


\section{REFERÊNCIAS}

AMORIM, Antonio Carlos Rodrigues; ARBAT, Eva Bau. Diagnósticos e intervenções sobre ambientalização curricular nos cursos de Licenciatura em Biologia e Geografia. Universidade Estadual de Campinas. In: JUNYENT, Mercè; GELI, Anna Maria; ARBAT, Eva (Orgs.). Procesos de diagnóstico de la Ambientalización Curricular de los Estudios Superiores. Girona: Universidad de Girona, v. 3, 2003, p. 93-130.

ARBAT, Eva; GELI, Anna Maria (Eds.) Ambientalización curricular de los estudios superiores - 1. Aspectos Ambientales de les universidades. Girona: Universitat de Girona-Red ACES, 2002, v. 1, 201p.

BOLEA, Yolanda; GRAU, Antoni; DOMINGO, Juan; MARTINEZ, Herminio. Ambientalización Curricular de los Estudios de Informática Industrial: La experiencia en la UPC. JORNADAS DE ENSEÑANZA UNIVERSITARIA DE INFORMÁTICA: ROBÓTICA E INFORMÁTICA INDUSTRIAL, 10., 2004, Anais... Alicante, Espanha: Editora da Universidade de Alicante, 2004, p. 443-451.

BRASIL. Ministério da Educação. Conselho Nacional de Educação - CNE. Resolução n. 2, de 15 de junho de 2012. Estabelece as Diretrizes Curriculares Nacionais para a Educação Ambiental. Brasília: MEC/CNE, 2012.

. Programa Nacional de Educação Ambiental - ProNEA. MMA Diretoria de Educação Ambiental; Ministério da Educação. Coordenação Geral de Educação Ambiental. 3. ed. Brasília: Ministério do Meio Ambiente, 2005.

. Lei 9.795, de 27 de abril de 1999. Dispõe sobre a educação ambiental, institui a Política Nacional de Educação Ambiental - PNEA e dá outras providências. Diário Oficial da República Federativa do Brasil, Brasília, DF, Brasília, 28 abr. 1999.

CADEP. Comisión sectorial de la CRUE para la Calidad ambiental, el Desarrollo sostenible y la prevención de riesgos. Evaluación de las políticas universitarias de sostenibilidad como facilitadoras para el desarrollo de los campus de excelencia internacional. España: Madrid: Ministerio de Educación/CADEP. 2010. 34p.

CARVALHO, Isabel Cristina de Moura; SILVA, Rosane Souza da. Ambientalização do ensino superior e a experiência da Pontifícia Universidade Católica do Rio Grande do Sul. In: RUSCHEINSKY, A. et al. Ambientalização nas instituições de educação superior no Brasil: caminhos trilhados, desafios e possibilidades. São Carlos: EESC/ USP, 2014. p. 125-144.

CARVALHO, Luis Marcelo; CAVALARI, Rosa Maria F.; SANTANA, Luiz Carlos. O processo de ambientalização curricular da UNESP - Campus de Rio Claro. Diagnóstico e perspectivas. In: GELI, Anna Maria; JUNYENT, Mercè; SÁNCHEZ, Sara (Eds.). Ambientalización curricular de los estudios superiores 3 - Diagnóstico de la Ambientalización Curricular de los Estudios Superiores. Girona: Universitat de Girona - Red ACES, 2003, v. 3, p. 131-165. 
COPELLO LEVY, Maria Ines. Escola ambientalizada e formação de professor@s: compromissos e desafios. In: TAGLIEBER, José Erno; GUERRA, Antonio Fernando Silveira (Orgs.). Pesquisa em Educação Ambiental: pensamentos e reflexões. Pelotas, UFPel, 2004, p. 105-143.

. Fundamentos teóricos e metodológicos de pesquisas sobre ambientalização da escola. Pesquisa em Educação Ambiental, v. 1, n. 1, p. 93-110, jul./dez., 2006.

FIGUEIREDO, Mara Lúcia; GUERRA, Antonio Fernando Silveira; CARLETTO, Denise Lemke. Ambientalização nas Instituições de Educação Superior: reflexões do IV Seminário Sustentabilidade na Universidade. In: RUSCHEINSKY, Aloísio; GUERRA, Antonio Fernando Silveira; FIGUEIREDO, Mara Lúcia; LEME, Patrícia Cristina Silva; RANIERI, Victor Eduardo Lima; DELITTI, Welington Braz Carvalho. Ambientalização nas Instituições de Educação Superior no Brasil: caminhos trilhados, desafios e possibilidades. São Carlos: EESC/USP, 2014. p. 337-349.

FÓRUM Internacional de Ongs e Movimentos Sociais. Tratado das ONGs: aprovados no Fórum Internacional de Organizações Não Governamentais e Movimentos Sociais, no Âmbito do Fórum Global - ECO 92. Rio de Janeiro: Fórum, 1992.

FREITAS, Denise; OLIVEIRA, Haydée Torres de; COSTA, Gislaine Gomes da; KLEIN, Priscilla. Diagnóstico do grau de ambientalização curricular no ensino, pesquisa, extensão e gestão na Universidade Federal de São Carlos (Brasil). In: GELI, Anna Maria; JUNYENT, Mercè; SÁNCHEZ, Sara (Eds.) Diagnóstico de la Ambientalización Curricular de los Estudios Superiores. Ambientalización curricular de los estudios superiores, v. 3. Girona: Universitat de Girona - Red ACES, 2003. p. 177-190.

GELI, Anna Maria. Introdução. Universidade, sustentabilidade e ambientalização curricular. In: GELI, Anna Maria; ARBAT, Eva (Eds.). Ambientalización curricular de los Estúdios Superiores: Aspectos ambientales de las Universidades. v. 1. Girona: Universitat de Girona - Red ACES, 2002. p. 15-18.

GELI, Anna Maria; JUNYENT, Mercè; SÁNCHEZ, Sara (Eds.). Diagnóstico de la Ambientalización Curricular de los Estudios Superiores. Ambientalización curricular de los estudios superiores, v. 3. Girona: Universitat de Girona - Red ACES, 2003.

GONZÁLES MUÑOZ, Maria C. Principales tendencias y modelos de la educación ambiental en el sistema escolar. Revista ibero-americana de educación, n. 11, p. 13-74, 1996.

GUERRA, Antonio Fernando Silveira; FIGUEIREDO, Mara Lúcia. Caminhos e desafios para a ambientalização curricular nas Universidades: panorama, reflexões e caminhos da tessitura do Programa Univali Sustentável. In: RUSCHEINSKY, Aloísio; GUERRA, Antonio Fernando Silveira; FIGUEIREDO, Mara Lúcia; LEME, Patrícia Cristina Silva; RANIERI, Victor Eduardo Lima; DELITTI, Welington Braz Carvalho. Ambientalização nas instituições de educação superior no Brasil: caminhos trilhados, desafios e possibilidades. São Carlos: EESC/USP, 2014. p. 145-164.

. Sustentabilidades em diálogos. Itajaí: Univali, 2010, p. 171-189. 
GUERRA, Antonio Fernando Silveira; FIGUEIREDO, Mara Lúcia; SAENZ, Orlando. (Coords.). II Jornada Ibero-americana da ARIUSA. Itajaí: Editora da Univali, 2012. p. 99-105.

GUERRA, Antonio Fernando Silveira; FIGUEIREDO, Mara Lúcia; SCHMIDT, Elisabeth Brandão. Ambientalização curricular em cursos de licenciatura e na educação básica: a pesquisa e a formação inicial e continuada. In: GUERRA, Antonio Fernando Silveira; FIGUEIREDO, Mara Lúcia; SAENZ, Orlando (Coords.). II Jornada Ibero-americana da ARIUSA. Itajaí: Editora da Univali, 2012a, p. 99-105.

. Educação para a sustentabilidade: formação inicial e continuada para ambientalização curricular nos cursos de licenciatura e na educação básica. In: REBOLO, F.; TEIXEIRA, L. R. M.; PERRELLI, M. A. Docência em questão: discutindo trabalho e formação. Campinas-SP: Mercado das Letras, 2012b, p. 229-263.

JUNYENT, Mercè; GELI, Anna Maria; ARBAT, Eva. Características de la ambientalización curricular: Modelo ACES. In: JUNYENT, Mercè; GELI, Anna Maria; ARBAT, Eva (Orgs.). Ambientalización Curricular de los Estudios Superiores. Proceso de Caracterización de la Ambientalización Curricular de los Estudios Superiores. Girona: Universitat de Girona - Red ACES, 2003. v. 2, p. 15-32.

KITZMANN, Dione. Ambientalização de Espaços Educativos: aproximações metodológicas. Rev. Eletrônica Mestr. Educ. Ambient., v. 18, p. 553-574, 2007.

KITZMANN, Dione; ASMUS, Milton Luis. Ambientalização sistêmica - do currículo ao socioambiente. Currículo sem Fronteiras, v. 12, n. 1, p. 269-290, jan./abr. 2012.

LEFF, Enrique. Epistemologia Ambiental. São Paulo: Cortez, 2002.

LEME, Patrícia Cristina Silva; PAVESI, Alessandra; ALBA, David; GONZÁLEZ, Maria JOSÉ Diaz. Visões e experiências ibero-americanas de sustentabilidade nas universidades. São Paulo-Madrid: USP-UAM, 2012.

MARCOMIN, Fátima E.; SILVA, A. D. V. da. A sustentável leveza da universidade. In: GUERRA, Antonio Fernando Silveira; FIGUEIREDO, Mara Lúcia. Sustentabilidades em diálogos. Itajaí: Univali, 2010. p. 171-189.

OLIVEIRA, Haydeé. T. O processo de ambientalização curricular na Universidade Federal de São Carlos nos contextos de ensino, pesquisa, extensão e gestão ambiental. In: CONGRESSO IBERO-AMERICANO DE EDUCAÇÃO AMBIENTAL, 5., Anais... Joinville-SC, abril 2006. p. 453-458.

OLIVEIRA JUNIOR, Wencesláo Machado de M.; GARGALLO, Josep Bonil; AMORIM, Antonio Carlos Rodrigues; ARBAT, Eva. As 10 características em um diagrama circular. In: JUNYENT, Mercè; GELI, Anna Maria; ARBAT, Eva. (Eds.). Ambientalización Curricular de los Estudios Superiores: aspectos Ambientales de les universidades. 2: proceso de caracterización de la Ambientalización Curricular de los Estudios Universitarios. Girona: Universitat de Girona, v. 2, p. 35-55, 2003. 
PAVESI, Alessandra; FARIAS, Carmen R.; OLIVEIRA, Haydeé Torres. Ambientalização da educação superior como aprendizagem institucional. Com Scientia Ambiental, v. 2, 2006.

REDE ACES. Red de Ambientalización Curricular de los Estudios Superiores. 2002. Disponível em: <http://insma.udg.es/ambientalitzacio/web_alfastinas/castella/c_index. htm>. Acesso em: 01/05/2013.

ROCKSTRÖM, Johan; STEFFEN, Will; NOONE, Kevin; PERSSON, Åsa; CHAPIN, F. Stuart; LAMBIN, Eric F. et al. A safe operating space for humanity. Nature, v. 461, n. 24, p. 472-475, set. 2009.

RUSCHEINSKY, Aloísio; GUERRA, Antonio Fernando Silveira; FIGUEIREDO, Mara Lúcia; LEME, Patrícia Cristina Silva; RANIERI, Victor Eduardo Lima; DELITTI, Welington Braz Carvalho (Orgs.). Ambientalização nas Instituições de Educação Superior no Brasil: caminhos trilhados, desafios e possibilidades. São Carlos: EESC/USP, 2014, 350 p.

SÁENZ, Orlando; BENAYAS, Javier. Educación Superior, Ambiente y Sustentabilidad en América Latina y el Caribe. In: GUERRA, Antonio Fernando Silveira; FIGUEIREDO, Mara Lúcia; SÁENZ, Orlando (Coords.). II Jornada Ibero-americana da ARIUSA. Itajaí: Editora da Univali, 2012. p. 99-105.

SANMARTÍ, N.; PUJOL, Rosa Maria. ¿Qué comporta capacitar para la acción? Sevilla, Investigación en la Escuela, n. 46, p. 49-54, 2002.

SANTOS, Rita S.; FREITAS, José Vicente de. Políticas públicas e institucionais para a incorporação dos temas ambiente e sustentabilidade nas instituições de educação superior. In: RUSCHEINSKY, Aloísio; GUERRA, Antonio Fernando Silveira; FIGUEIREDO, Mara Lúcia; LEME, Patrícia Cristina Silva; RANIERI, Victor Eduardo Lima; DELITTI, Welington Braz Carvalho (Orgs.). Ambientalização nas Instituições de Educação Superior no Brasil: caminhos trilhados, desafios e possibilidades. São Carlos: EESC/ USP, 2014. p. 283-296.

TRAJBER, Rachel; SATO, Michéle Escolas sustentáveis: incubadoras de transformações nas comunidades. Rev. Eletrônica Mestr. Educ. Ambient., v. especial, p. 70-78, set. 2010.

TRISTÃO, Martha. Espaços/tempos de formação em Educação Ambiental. In: TAGLIEBER, José Erno; GUERRA, Antonio Fernando Silveira (Orgs.). Educação ambiental: fundamentos, práticas e desafios. Itajaí: Universidade do Vale do Itajaí, 2007, p. 37-51. (Coleções Plurais Educacionais).

Texto recebido em 09 de outubro de 2014. Texto aprovado em 13 de outubro de 2014. 